\title{
CUTANEOUS MANIFESTATIONS IN PATIENTS WITH CHRONIC KIDNEY DISEASE ON HEMODIALYSIS AND IT'S CORRELATION WITH RENAL FUNCTION, DIALYSIS CYCLE AND HAEMOGLOBIN
}

\author{
Pradhan $\mathrm{M}^{1^{*}}$, Chhetri $\mathrm{G}^{2}$, Rai $D^{3}$, Paudel $S^{4}$
}

\section{Affiliation}

1. Lecturer, Department of Dermatology, Nobel Medical College, Biratnagar Nepal

2. Lecturer, Department of Medicine, Nobel Medical College, Biratnagar Nepal

3. Resident, Department of Dermatology, Nobel Medical College, Biratnagar Nepal

4. Intern, Nobel Medical College, Biratnagar Nepal

A R T I C L E I N F O
Article History
Received : 18 June, 2018
Accepted : 12 August, 2018
Published : 31 August, 2018

(C) Authors retain copyright and grant the journal right of first publication with the work simultaneously licensed under Creative Commons Attribution License CC - BY 4.0 that allows others to share the work with an acknowledgment of the work's authorship and initial publication in this journal.

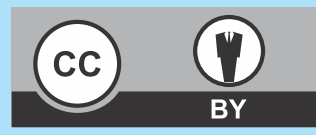

\section{ORA 77}

DOI : http://dx.doi.org/10.3126/bjhs.v3i2.20963

* Corresponding Author

Dr. Manish Pradhan

Lecturer

Department of Dermatology and Venerology

Nobel Medical College Teaching Hospital, Biratnagar

Email:drmanishpradhan1@gmail.com

ORCID: https://orcid.org/0000-0001-6817-4160

\section{Citation}

Pradhan M, Chhetri G, Rai D, Paudel S. Cutaneous Manifestations In Patients With Chronic Kidney Disease On Hemodialysis And It's Correlation With Renal Function, Dialysis Cycle And Haemoglobin. BJHS 2018;3(2)6:468-474.

\section{ABSTRACT}

\section{Introduction}

Skin is the mirror of an internal disease, including the renal system. Chronic kidney disease presents with variety of skin diseases, which is caused either by kidney disease or by treatment modalities.

\section{Objective}

To evaluate the prevalence of various skin disease in patients with chronic renal disease and relation of various skin diseases with serum creatinine, blood urea, hemoglobin and number of hemodialysis cycle.

\section{Methodology}

A cross-sectional analytical study was conducted in hundred patients of either sex, aged 18 years and above; with chronic kidney disease (stage V) admitted for dialysis in Nephrology department of Nobel Medical College and teaching hospital, Biratnagar, Nepal. The study groups were evaluated for various skin manifestation and parameters of renal function like blood urea and serum creatinine.

\section{Results}

Among the total patients $(n=100), 84$ patients presented with complain of skin manifestation but on detail examination 97 patients had at least one skin disease. The causes leading to chronic kidney disease were found to be hypertension $58 \%$, diabetes mellitus $49 \%$, IgA nephropathy $7 \%$, systemic lupus erythematosus $7 \%$ and glomerulonephritis $4 \%$. Xerosis was the commonest skin disease encountered in these patients amounting to $71 \%$ among which 43 were hypertensive and 34 were diabetic. Xerosis was followed by pruritus (62\%), pallor (54\%), mucosal changes (39\%), skin infection (36\%), hair changes (34\%), pigmentation (33\%) and nail changes (29\%). Serum creatinine showed statistically significant association with pruritus $(p=0.030)$ and pigmentation $(p=0.010)$, similarly blood urea showed significant association with pruritus $(p=0.001)$. Similarly, number of dialysis cycle showed significant association with pigmentation of $\operatorname{skin}(p=<0.001)$.

\section{Conclusion}

Chronic kidney disease is associated with variety of skin diseases. The commonest were xerosis and pruritus. Early detection and appropriate intervention can relieve and decrease suffering.

\section{KEY WORDS}

hemodialysis, kidney disease, skin disease 


\section{INTRODUCTION}

Chronic kidney disease (CKD) is a progressive loss of kidney function over a period of months or years through five stages. It is defined as kidney damage or glomerular filtration rate $<60 \mathrm{ml} / \mathrm{min} / 1.73 \mathrm{~m}^{2}$ for months or more irrespective of the cause.

Skin is the mirror of an internal disease, and it has always helped the clinician to diagnose systemic diseases. As we know, CKD presents with an array of skin diseases; from benign and asymptomatic to the physically disabling and life threatening. ${ }^{2}$ Many of them, have a debilitating effect on quality of life. These skin disease can occur before dialysis or following the initiation of hemodialysis treatment. ${ }^{3}$ It has been found that $82 \%$ patients with end stage renal disease have at least one associated cutaneous change. ${ }^{4}$

As the incidence and prevalence of chronic kidney disease is increasing day by day in this modern world; the incidence and prevalence of associated skin diseases are also increasing. So, their early recognition and treatment is quite essential to reduce morbidity and mortality. ${ }^{3}$ The prevalence of cutaneous manifestation is high among dialysis patients. This occurs because of numerous factors such as uremia, metabolic disorders, dialysis and side effects of immunosuppressive drugs. ${ }^{5}$

Some of these skin diseases disappear following kidney transplantation, confirming that the metabolic milieu resulting from the malfunctioning kidney is responsible for some of these changes. ${ }^{6}$

Patients on hemodialysis (HD) are known to develop skin diseases ranging from infections to malignancies. In addition, new cutaneous lesions may develop with increasing age. Sometimes, cutaneous changes maybe the first important sign in patients with chronic renal failure. ${ }^{5}$ Moreover, skin diseases are generally seen in patients with moderate renal impairment (CKD stage 3 and 4) before progressing to End Stage Renal Disease; so persistent xerosis or intractable pruritus commends for further search for underlying renal impairment.

Though important for maintenance of homeostasis in patients with End stage renal disease (ESRD), neither dialysis is efficient in removing substances compared to healthy kidneys nor can it replace other endocrine functions lost with renal failure leading to various metabolic disorders and associated skin complications. ${ }^{7}$ With advancement of technology and improved dialysis therapy in the west, cutaneous complications in patients with renal disease are in decreasing trend; unlike the case in developing countries like Nepal. Moreover, the ignorant Nepalese population is subjected to harmful effects of tropical climate, with the associated higher incidence of infections and malnutrition; all contributing to the skin diseases in CKD patients.

Because skin diseases may have a cosmetically destructive effect, in addition to complications such as pruritus that disturbs the patient's comfort, this study was done to determine the prevalence of mucocutaneous manifestations in patients on hemodialysis along with relation of various skin disorders with the parameters of renal function like serum creatinine, blood urea, hemoglobin and number of dialysis cycles.

\section{METHODOLOGY}

In this cross sectional, analytic study; 100 patients of either sex, aged 18 years and above; admitted with the diagnosis of CKD for dialysis in Nephrology department of Nobel Medical College and teaching hospital, Biratnagar, Nepal, recruited during the period of January 2017 to December 2017, were chosen randomly as candidates for the study after taking ethical clearance from the institutional review board. Written consent was obtained from all candidates. All the patients were examined in detail by dermatologist in a location with adequate light. Diagnosis of the disease was made clinically. Demographic details like age, sex, cause of renal failure, duration on dialysis was taken from patient's files. Information about patients' laboratory tests was obtained from mean of three recent tests.

\section{Inclusion criteria}

Patients with chronic kidney disease (stage V) of age above 18 years undergoing hemodialysis.

\section{Exclusion criteria for cases}

Patients with acute renal failure, patients who had undergone renal transplantation and who had undergone peritoneal dialysis

The normal value for serum creatinine, blood urea and hemoglobin was taken to be $0.6-1.2 \mathrm{mg} / \mathrm{dl}, 7-20 \mathrm{mg} / \mathrm{dl}$ and $12-16 \mathrm{gm} / \mathrm{dl}$ respectively.

\section{Statistical Analysis}

Data were analyzed using SPSS software (Version 22). The Independent t-Test was used to evaluate the association of skin disease with serum creatinine, blood urea, hemoglobin and number of dialysis cycle and chi-square test was used with for qualitative data. $P$ value was calculated and less than 0.05 was considered to be statistically significant.

\section{RESULT}

Out of total 100 patients enrolled in the study, 59\% $(n=59)$ were male and $41 \%(n=41)$ were female. The mean age (years) of the patients was 55.81 \pm 17.94 , youngest being 18 and oldest being 88 . The duration of chronic kidney disease varied from 1 month and several years and the mean of dialysis cycles done was $11.43 \pm 16.11$; with the minimum cycle being 2 and maximum cycle being 106 . The causes leading to chronic kidney disease were found to be hypertension in 58\%; among them 38\% were male and $20 \%$ were female; diabetes mellitus $49 \%$; among them, male were $30 \%$ and female were $19 \%$; IgA nephropathy $7 \%$, systemic lupus erythematosus 7\%; among them females were 6 and male, and glomerulonephritis in 4\%, as shown in Table 1. Among the patients having chronic kidney disease, 27 were suffering from both hypertension and diabetic mellitus.

Among the total patients $(n=100), 84$ patients presented with complain of skin manifestation but on detail examination 97 patients had at least one skin disease. Xerosis was the most common skin disease seen in these patients, and this was seen in $71 \%$ of the patients among which 43 were hypertensive and 34 were diabetic. Xerosis was followed by pruritus seen in $62 \%$, pallor seen in $54 \%$, mucosal changes seen in $39 \%$, skin infection seen in $36 \%$ (fungal=21\%, bacterial $9 \%$ and viral=6\%), pigmentation seen in 33\% (29\% hyperpigmentation and $6 \%$ yellow tinge), nail changes seen in $29 \%$ and hair changes in 34\%as shown in Table 1. 
Other skin disease observed in our study were alopecia areata in 2 patients, followed by ecchymoses in 1 , acneform eruptions in 1 , seborrhoeic keratosis in 1 , eczema in 1 and lichen planus in 1.

The mean serum creatinine was $11.44 \pm 5.81 \mathrm{mg} / \mathrm{dl}$ with minimum of $1.4 \mathrm{mg} / \mathrm{dl}$ and maximum $28 \mathrm{mg} / \mathrm{dl}$. Similarly blood urea was $159.18 \pm 51.17 \mathrm{mg} / \mathrm{dl}$ with minimum of $22 \mathrm{mg} / \mathrm{dl}$ and maximum of $288 \mathrm{mg} / \mathrm{dl}$ in our study group. The independent-samples $T$ test was carried out between different dermatological manifestation and serum creatinine, blood urea, hemoglobin and number of dialysis. There was statistically significant association of serum creatinine with pruritus $(p=0.030)$ and pigmentation $(p=0.010)$. Similarly, blood urea shows significant association with pruritus ( $p=0.001)$. However all other skin, mucosal and nail changes did not show any association with serum creatinine and blood urea as shown in Table 2.

In the same way, mean hemoglobin in our study was $6.65 \pm$ $2.03 \mathrm{~g} / \mathrm{dl}$ with minimum of $2 \mathrm{~g} / \mathrm{dl}$ and maximum $10 \mathrm{~g} / \mathrm{dl}$. On further evaluation, hemoglobin was found to be statistically significant with pallor $(p=<0.001)$ and clubbing $(p=<0.001))$ in patient having chronic kidney disease undergoing hemodialysis. In our study, $14 \%$ had hemoglobin level less than $5 \mathrm{~g} / \mathrm{dl}$; $52 \%$ had hemoglobin levels between $5-8 \mathrm{~g} / \mathrm{dl}$ and $34 \%$ had hemoglobin level more than $8 \mathrm{~g} / \mathrm{dl}$. Similarly, number of dialysis cycle shows significant association with pigmentation of skin $(p=<0.001)$ and angular cheilitis $(p=<0.001)$. However, in our study there was no significant association of hemoglobin and number of dialysis cycle with other skin manifestation in patient of chronic kidney disease as shown in Table 3.

Chi square test illustrated the association between pruritus and patient with chronic kidney disease with diabetic mellitus $(p=0.044)$. However, there is no association of pruritus with chronic kidney disease with hypertension $(p=0.145)$. Similarly xerosis shows no significant association with chronic kidney disease with diabetic mellitus and hypertension ( $p=0.449$ and $p=0.277$ respectively).

TABLE 1: The causes of chronic kidney disease (stage V) and prevalence of dermatological manifestation in patients undergoing dialysis.

\begin{tabular}{|c|c|c|c|c|c|c|}
\hline $\begin{array}{l}\text { Dermatological } \\
\text { manifestation }\end{array}$ & $\begin{array}{c}\text { Total } \\
100(100 \%)\end{array}$ & $\begin{array}{c}\text { Hypertension } \\
58(58 \%)\end{array}$ & $\begin{array}{l}\text { Diabetic } \\
\text { Mellitus } \\
49(49 \%)\end{array}$ & $\begin{array}{c}\text { SLE } \\
7(7 \%)\end{array}$ & $\begin{array}{c}\text { Glomerulo- } \\
\text { nephritis } \\
4(4 \%)\end{array}$ & $\begin{array}{c}\text { IgA nephropathy } \\
\mathbf{7 ( 7 \% )}\end{array}$ \\
\hline
\end{tabular}

\section{Skin changes}

\begin{tabular}{|c|c|c|c|c|c|c|}
\hline Xerosis & 71 (71\%) & 43 & 34 & 4 & 3 & 6 \\
\hline Pruritus & $62(62 \%)$ & 39 & 35 & 5 & 2 & 4 \\
\hline Pallor & $54(54 \%)$ & 34 & 25 & & 1 & 3 \\
\hline Acquired perforating & & & & 3 & & \\
\hline dermatoses & $2(2 \%)$ & - & 2 & - & - & - \\
\hline Pigmentation & $33(33 \%)$ & 24 & 19 & - & - & 1 \\
\hline \multicolumn{7}{|l|}{ Skin infection } \\
\hline Fungal & $21(21 \%)$ & 11 & 10 & 2 & 1 & 1 \\
\hline Bacterial & $9(9 \%)$ & 5 & 4 & 1 & - & 2 \\
\hline Viral & $6(6 \%)$ & 3 & 4 & - & - & \\
\hline \multicolumn{7}{|l|}{ Nail changes } \\
\hline Half and half nails & $8(8 \%)$ & 5 & 5 & - & - & - \\
\hline Leuconychia & $7(7 \%)$ & 2 & 3 & 1 & - & 1 \\
\hline Longitudinal ridges & $7(7 \%)$ & 4 & 4 & - & 1 & - \\
\hline Onychomycosis & $13(13 \%)$ & 8 & 8 & - & - & 1 \\
\hline Clubbing & $3(3 \%)$ & 3 & 1 & - & - & \\
\hline \multicolumn{7}{|l|}{ Mucosal changes } \\
\hline Xerostomia & 32 (32\%) & 22 & 16 & - & 1 & 2 \\
\hline Macroglossia & $22(22 \%)$ & 13 & 10 & 1 & 2 & - \\
\hline Fissured tongue & $11(11 \%)$ & 7 & 4 & - & 1 & - \\
\hline Ulcerative stomatitis & $7(7 \%)$ & 5 & 3 & - & 2 & - \\
\hline Angular cheilitis & $4(4 \%)$ & 3 & 1 & - & - & - \\
\hline
\end{tabular}

\begin{tabular}{|c|c|c|c|c|c|c|c|}
\hline \multicolumn{8}{|c|}{ Hair changes } \\
\hline \multirow{2}{*}{\multicolumn{2}{|c|}{$\begin{array}{l}\text { Sparse scalp hair } \\
\text { Brittle lusterless }\end{array}$}} & $23(23 \%)$ & 16 & 14 & - & - & - \\
\hline & & & & & & & \\
\hline \multicolumn{2}{|l|}{ hair } & $11(11 \%)$ & 6 & 6 & - & - & - \\
\hline \multicolumn{2}{|c|}{ Others } & $7(7 \%)$ & 3 & 4 & - & - & - \\
\hline \multicolumn{2}{|l|}{ None } & $3(3 \%)$ & 1 & 1 & 1 & 1 & - \\
\hline \multirow{2}{*}{470} & \multicolumn{7}{|c|}{ Birat Journal of Health Sciences } \\
\hline & \multicolumn{7}{|c|}{ Vol.3/No.2/Issue 6/ May-August 2018} \\
\hline
\end{tabular}


TABLE 2: Relation of various dermatological manifestation in chronic kidney disease with serum creatinine and blood urea using independent-samples t-Test.

Dermatological

Serum creatinine $(\mathrm{mg} / \mathrm{dl})$

Blood urea (mg/dl)

manifestation

Mean \pm S.D. P value

Mean \pm S.D.

P value

Skin changes

Xerosis

$11.46 \pm 5.75$

0.943

$159.06 \pm 49.80$

0.971

Pruritus

$12.78 \pm 5.97$

$0.030 *$

$172.69 \pm 41.94$

$0.001^{*}$

Pallor

$11.33 \pm 5.55$

0.848

$162.34 \pm 54.56$

0.505

Skin infection

$10.38 \pm 5.35$

0.176

$147.86 \pm 47.94$

0.097

Acquired perforating dermatoses

$9.15 \pm 1.34$

0.577

$124.00 \pm 59.40$

0.329

Pigmentation

$13.56 \pm 6.31$

$0.010 *$

$170.36 \pm 50.98$

0.126

\section{Nail changes}

Half and half nails

$8.54 \pm 3.69$

0.142

$126.95 \pm 41.17$

0.06

Leuconychia

$12.74 \pm 7.62$

0.539

$176.57 \pm 49.55$

0.354

Longitudinal ridges

$13.23 \pm 4.31$

0.400

Onychomycosis

$11.24 \pm 5.35$

0.897

$169.43 \pm 33.75$

0.585

Clubbing

$6.50 \pm 2.26$

0.136

$155.54 \pm 54.90$

0.785

Mucosal changes

Xerostomia

Macroglossia

$11.95 \pm 6.55$

$110.53 \pm 69.21$

0.095

Fissured tongue

Ulcerative stomatitis

Angular cheilitis

$10.39 \pm 5.91$

0.543

$158.74 \pm 56.81$

0.953

$12.11 \pm 6.85$

0.340

$152.86 \pm 56.76$

0.515

$13.23 \pm 7.62$

0.685

$168.15 \pm 71.83$

0.540

$11.35 \pm 5.27$

0.400

$162.86 \pm 67.94$

0.845

\section{Hair changes}

Sparse scalp hair

Brittle lusterless hair

Total

$12.27 \pm 6.85$

0.976

$153.00 \pm 86.11$

0.807

*Statistically significant at $\mathrm{p}<0.05$.

TABLE 3: Relation of various dermatological manifestations in chronic kidney disease with hemoglobin and number of hemodialysis using independent-samples t-Test.

Dermatological

Hemoglobin $(\mathbf{g} / \mathrm{dl})$

manifestation

$13.16 \pm 5.72$

0.435

$172.00 \pm 42.78$

0.172

$11.44 \pm 5.81$

$147.46 \pm 62.79$

0.423

$159.18 \pm 51.17$

\section{Skin changes}

Xerosis

Pruritus

Pallor

Infection

Acquired perforating dermatoses

Pigmentation

\section{Nail changes}

Half and half nails

Leuconychia

Longitudinal ridges Mean \pm S.D.

$P$ value

No. of hemodialysis cycle

Onychomycosis

Clubbing

$6.59 \pm 1.94$

0.654

0.236

$6.84 \pm 2.06$

$5.11 \pm 1.21$

$<0.001$ *

$6.47 \pm 1.70$

0.513

$9.00 \pm 0.00$

0.098

$6.85 \pm 2.02$

0.495 Mean \pm S.D.

$P$ value

\section{Mucosal changes}

Xerostomia

Macroglossia

Fissured tongue

Ulcerative stomatitis

Angular cheilitis

\section{Hair changes}

Sparse scalp hair

Brittle lusterless hair

Total

$11.13 \pm 15.95$

0.770

$10.85 \pm 13.09$

0.651

$9.78 \pm 11.69$

0.291

$12.75 \pm 15.25$

0.541

$4.00 \pm 1.41$

0.513

$24.30 \pm 23.12$

$<0.001^{*}$

*Statistically significant at $p<0.05$.

$5.63 \pm 1.69$

0.137

$6.71 \pm 2.98$

0.931

$6.14 \pm 2.19$

0.495

$5.92 \pm 1.75$

0.167

$2.67 \pm 0.58$

$<0.001$ *

$6.75 \pm 1.92$

0.737

0.387

\section{$6.32 \pm 1.84$}

$6.36 \pm 2.66$

$7.29 \pm 2.36$

$8.00 \pm 2.00$

$6.09 \pm 1.90$

$6.18 \pm 1.89$

$6.65 \pm 2.03$

0.130

0.622

0.392

0.175

$6.63 \pm 4.44$

0.382

$4.71 \pm 2.63$

$7.86 \pm 6.64$

0.255

$12.08 \pm 14.35$

$5.00 \pm 1.73$

0.878

0.485 


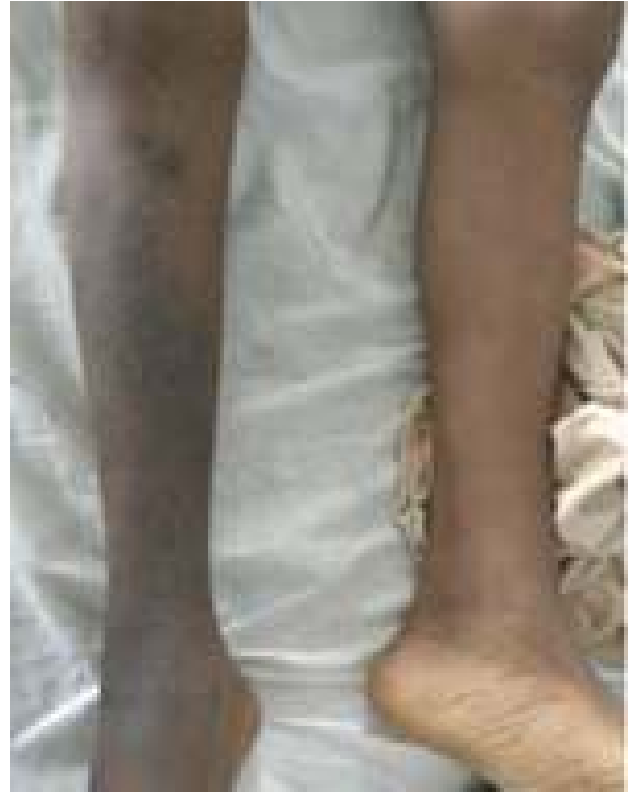

Figure 1: Pigmentary changes in patient with CKD on hemodialysis

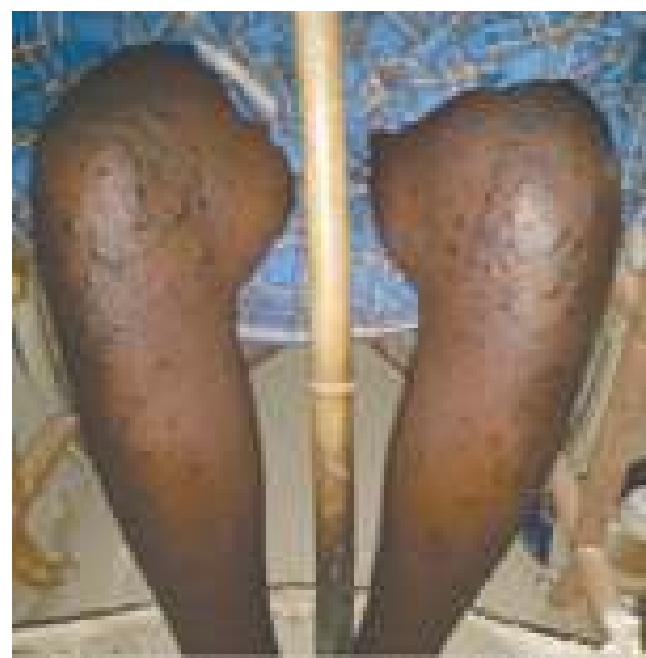

Figure 2: Acquired Perforating Dermatosis in patient with CKD on hemodialysis

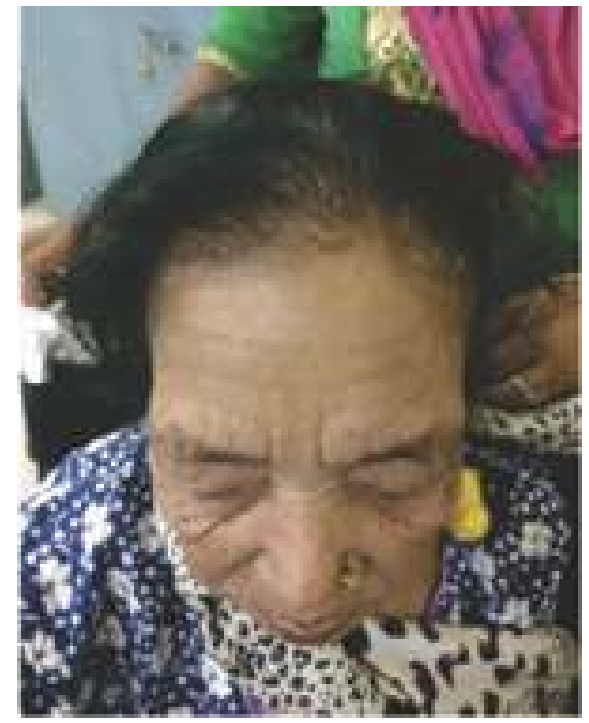

Figure 3: Sparse hair in patient with CKD hemodialysis

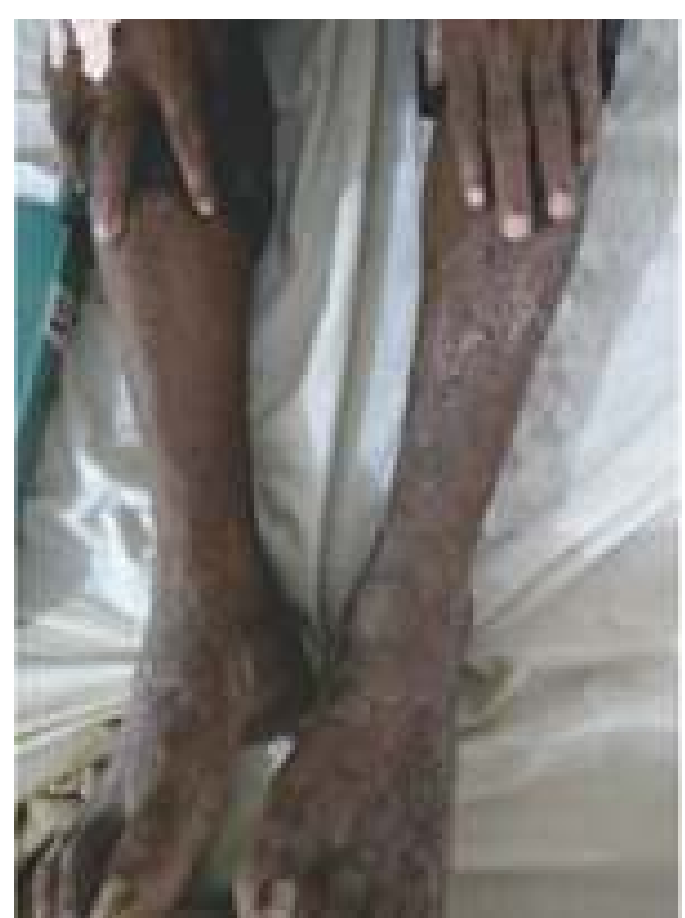

Figure 4: Eczema in patient with CKD on hemodialysis

\section{DISCUSSSION}

Patients with chronic kidney disease who were on hemodialysis presented with a wide spectrum of skin diseases, which is quite a fact as $97 \%$ of the patients in our study, showed at least one skin disease.

Xerosis was the most common finding in our study, which was seen in $71 \%$ of the patients in our study. Like our result Udaykumar et al. reported it in $79 \%$ of the patients and Baghel et al. reported it to be seen in $66.2 \% .{ }^{4,5}$ In contrast to our result, Gurucharan et al. reported high result with $90 \%$ of the patients and Hajheydari et al. reported it to be seen in only $22.8 \%{ }^{8,9}$ In Nepal, Shrestha P et al. reported it to be seen in $54 \%$ of the patients on hemodialyisis. ${ }^{2}$ Amatya B et al. did study on CKD patients including patients on dialysis and medical treatment and found xerosis in $28 \%$ of patietns. ${ }^{10}$ The difference in result may be due to patient skin type, primary disease leading to CKD, drugs used in treatment and difference in climatic condition of patience residence. Xerosis may be due to reduced size and function of eccrine sweat gland or may due to use of high dose of diuretics. ${ }^{4}$

Pruritus was present in $62 \%$ of our patients. The severity of pruritus varied and some patient gave history of improvement of pruritus after dialysis. There was significant relation of pruritus with blood urea and serum creatinine level. Dyanchenko $P$ et al. reported pruritus in $74.3 \%$ of hemodialysis patients at some point. ${ }^{11}$ Udaykumar et al. reported it in $53 \%$ of the patients, Baghel et al. reported it to be seen in $51.25 \%$, Hajheydari et al. found in $38.6 \%$ patients and Pico et al. reported pruritus in $42 \%$. ${ }^{4,5,9,12}$ In Nepal, Shrestha $\mathrm{P}$ et al. reported pruritus in $40 \%$ of the patients and Amatya B et al. in $15 \%$ of the patients. ${ }^{2,10}$ The exact 
cause of increased itching in CKD patient in unknown. Hemodialysis can initiate the symptom as well as improve it. It may be due to increased serum histamine levels because of allergic sensitization to diverse dialyzer membrane components as well as impairing renal excretion of histamine. There is an abnormal pattern of cutaneous innervations in CKD, which occurs due to slowly accumulated pruritogen, the nature of which is uncertain. ${ }^{4,5}$ It may be secondary to anemia, xerosis, hypervitaminosis $A$, secondary hyperparathyroidism or increase levels of magnesium, calcium and phosphates and serum histamine. ${ }^{4}$

Another manifestation commonly seen in our patient was pallor, which was seen in $54 \%$ of patient. It was significantly associated with hemoglobin level. It is an early and common sign in renal failure resulting from reduced erythropoiesis and increased haemolysis. ${ }^{5}$ Udaykumar et al. reported pallor in $60 \%$ patients, Baghel et al. reported in $57.5 \%$ patients and Dyanchenko et al. in $75.7 \%$ patients on haemodialysis. ${ }^{4,5,11}$

Pigmentary changes were seen in $33 \%$ of patients and there was significant relationship between pigmentary changes with serum creatinine level and number of dialysis cycles. Hyperpigmentation was seen in $29 \%$ of the patient and yellow tinge on the skin was seen in $5 \%$ of the patients. Result of pigmentary changes in CKD are variable. Udaykumar et al. reported pigmentary changes in $43 \%$ of patients and Baghel et al. reported in $13.75 \%$ of patients whereas Hajheydari et al. reported in $66.3 \%$ patients, Dyanchenko et al. in $75.7 \%$ patients, and Pico et al reported diffuse pigmentation in $70 \%$ patients. ${ }^{9,11,12}$ In Nepal Shrestha P et al. and Amatya B et al. reported it in $35 \%$ and $20 \%$ of the patients respectively., ${ }^{210}$ Hyperpigmenatation of the skin in CKD patient is attributed to increasing level beta melanocyte stimulating hormone due to its decreased excretion in CKD patient. A yellowish tinge has been attributed to deposition of carotenoids and nitrogenous pigments in the dermis or the presence of lipochromes and carotenoids in the epidermis and subcutaneous tissue. ${ }^{13}$ There are reports of hypopigmentary skin changes in CKD like vitiligo and postinflammatoryhypopigmentation, which was not found in our patients. ${ }^{4,5}$

Perforating disorders such as perforating folliculitis, Kyrels disease and reactive perforating collagenosis have been described in CKD. ${ }^{14}$ In our study perforating dermatosis was seen in $2 \%$ of the patients. Trauma to the skin secondary to xerosis and pruritus may be the cause for this. Ashokan et al. reported perforating disorder in $7.5 \%$ of patients, Uday kumar et al. in $21 \%$ patients and Baghel et al. in $2.5 \%$ of the patients. ${ }^{3,45}$

Infection was also seen in major group of study population in $36 \%$. The major type of infection was fungal infection (21\%) followed by pyodermas (9\%) and viral infection (6\%).Udaykumar et al. reported fungal infection in (30\%), bacterial in (13\%) and viral in (12\%). ${ }^{4}$ Ashokan et al. reported infection in $17.5 \%$ of the patients and Amatya B et al. reported infection in only $5 \%$. $^{3,10}$

Nail changes was seen in $29 \%$ of the patients. Half and half nail, leuconychia, longitudinal ridges, onychomycosis and clubbing were seen. Nail changes were reported by Ashokan et al. in $21.67 \%$ and Udaykumar et al. reported in $21 \%$ patients, of the patients like our relsult. ${ }^{3,4}$ Contradicting with our result Shrestha P et al. reported in $62 \%$ and Amatya Bet al. in $82 \%$ which was high compare to our result. ${ }^{2,10}$

Mucosal changes were seen in $39 \%$ of the patients. Xerostomia, macroglossia, fissured tongue, ulcerative stomatitis and angular cheilitis was seen. Shrestha P et al. reported mucosal changes in $22 \%$ patients, Ashokan et al. 7.5\% and Baghel et al. in $19 \%$ and of the patients. ${ }^{2,3,5}$

Hair changes were seen in $34 \%$ of the patients. Sparse scalp hair and brittle lusterless hair was the hair changes observed. Shrestha P et al. reported hair changes in $12 \%$ patients, Ashokan et al. in 15\% and Baghel et al. in $19 \%$ of the patients. ${ }^{2,3,5}$

In CKD patient skin changes like metastatic calcification of the skin, skin cancer, gynaecomastia, uremic frost, Nephrogenicfibrosingdermopathy has also been reported. ${ }^{3,}$ ${ }^{4}$ These findings were not observed in our patients. There has also a report of skin changes in AV fistula that was not observed in our study. ${ }^{3,4,5}$

Other miscellaneous skin findings were also observed in our patients, which may not be attributed to CKD and dialysis. Other findings observed were alopecia areata, ecchymoses, acneform eruptions, seborrhoeickeratosis, eczema and lichen planus.

\section{CONCLUSION}

Skin manifestations are common in patient with CKD. This increases morbidity in this patient with impairment in quality of life and they are resistant to treatment. In developing country like Nepal where dialysis facilities are available only in limited hospital proper evaluation and timely management of this condition can cause improvement in quality of life of these patients.

\section{RECOMMENDATIONS}

We recommend the patient with chronic kidney disease for early evaluation of skin disease and early intervention.

\section{LIMITATION OF STUDY}

The study could have been better if patient of CKD on medical treatment and patients with peritoneal dialysis were also included along with patient on hemodialysis.

\section{ACKONWLEDGEMENT}

We are very grateful to Dr Sailendra Shrestha for granting permission to evaluate and perform research on patient with chronic kidney disease.

\section{CONFLICT OF INTREST}

None

\section{FINANCIALDISCLOSURE}

None 


\section{REFERENCES}

1. Levey AS, Eckardt KU, Tsukamoto Y, Levin A, Ressert J. Definition and classification of chronic kidney desease: A position statement from kidney disease: Improving global outcomes (KDIGO). Kidney Int 2005 Jun; 67(6): 2089-100. PMID: 15882252.

2. Shrestha P, Mathur M. Dermatologic manifestations in chronic kidney disease patients on hemodialysis. NJDVL 2014; 12 (1): 34-40. DOI: $10.3126 /$ njdvl201412105.

3. Asokan S, Narasimhan M, Rajagopalan V. Cutaneous manifestations in chronic renal failure patients on hemodialysis and medical management. Int J Res Dermatol 2017:3:24-32. DOI: 10.18203/Int J Res Dermatol20170432.

4. Udayakumar P, Balasubramanian S, Ramalingam KS. Cutaneous manifestations in patients with chronic renal failure on haemodialysis. Indian J DermatolVenereolLeprol. 2006; 72:119-25. PMID: 16707817.

5. Baghel N, Awasthi S, Kumar SS. Cutaneous manifestations in patients with chronic kidney disease on hemodialysis. Int J Res Med Sci 2017; 5:1673-8. DOI: 10.18203/ijam20173217.

6. Falodun O, Ogunbiyi A, Salako B, George A. Skin changes in patients with chronic renal failure. Saudi J Kidney DisTranspl 2011; 22:268272. PMID: 21422624.

7. Khanna D, Singal A, Kalra OP. Comparison of cutaneous mani festations in chronic kidney disease with or without dialysis. Postgrad Med J 2010; 86:641-647. PMID: 21037238.
8. Singh $G$, Verma AV, Singh $G$, Singh SJ. Cutaneous changes in chronic renal failure. Ind J DermatolVenerolLeprol. 1998; 58:320-2. PMID: 28128158.

9. Hajheydari Z, Makhlough A. Cutaneous and mucosal manifestations in patients on maintenance haemodialysis. Iran J Kidney Dis. 2008; 2:86-90. PMID: 19377214.

10. Amatya B, Agrawal S, Dhali T, Sharma S, Pandey SS. Pattern of skin and nail changes in chronic renal failure in Nepal: a hospital based study. J Dermatol 2008 Mar; 35(3): 140-5. PMID: 18346256.

11. Dyanchenko P, Shustak A, Rozenman D. Hemodialysis-related pruritus and associated cutaneous manifestations.Int J Dermatol. 2006 Jun; 45(6): 664-7. PMID: 16796623.

12. Pico MR, KLugo-somolinos A, Sanchez JL, Burgos-claderon R. Cutaneous alterations in patients with chronic renal failure. Int J Dermatol 1992; 31:860-30. PMID: 1478764

13. Smith AG, Shuster S, Comaish JS, Plummer NA, Thody AJ, AlvarezUde F, Kerr DN. Plasma immunoreactive beta-melanocytestimulating hormone andskin pigmentation in chronic renal failure. Br Med J. 1975 Mar 22; 1(5959): 658-9. PMID: 1125653.

14. Heilman ER, Friedman RJ. Degenerative diseases and perforating disorders. In: Elder D, Elenitsas R, Jaworsky C, Johnson Jr. B, editors. Lever's histopathology of the skin. $8^{\text {th }}$ ed. Lippincott-Raven: Philadelphia; 1997. p. 341-51. Available from www. levershistopathology.com 